\title{
Management Accounting Practices (MAPs) Impact on Small and Medium Enterprise Business Performance within the Gauteng Province of South Africa
}

\author{
Mahdi Hasan Ahmed AlKhajeh ${ }^{1}$ and Azam Abdelhakeem Khalid ${ }^{2}$ \\ ${ }^{1}$ Faculty of Business and Accountancy, Lincoln University College, Malaysia \\ ${ }^{2}$ Faculty of Management and Economics, Universiti Pendidikan Sultan Idris, Malaysia
}

Correspondence should be addressed to: Mahdi Hasan Ahmed AlKhajeh; al_khajeh@hotmail.com

Received date: 10 May 2018; Accepted date: 30 May 2018; Published date: 06 July 2018.

Academic Editor: Rejaul Abedin

Copyright (C) 2018. Mahdi Hasan Ahmed AlKhajeh and Azam Abdelhakeem Khalid .Distributed under Creative Commons CC-BY 4.0

\begin{abstract}
The following article focuses on determining the effect of Management Accounting Practices (MAPs) on the performance of Small \& Medium sized Enterprises (SME). The SMEs studied in the research belong to the Gauteng Province of South Africa. The article has introduced different concepts that are used in this article like MAPs, small and medium-sized enterprises (SME), as well as the relationship between MAPs and the performance of an organization. The below article has also mentioned the reason because of which the authors of the mentioned article decided to choose this topic and explore the impact of MAPs on SMEs. The following article has also mentioned the secondary sources that the authors of this article have mentioned while using the work of different scholars who have conducted research on related topics. The methodology used in the mentioned article has been studied in details and has been mentioned in the below article with acute details. The Quantitative method has been used in the mentioned article in order to find out the results of the research. A well -structured questionnaire has been made by the authors of the article to survey the SMEs of the South African province of Gauteng. Regression analysis has been used by the authors to find out the impact of different MAPs on the performance of organizations (SMEs). The results of the regression analysis have been discussed in detail in the below article. And in the end, the conclusion has been included, which reflects that the MAPs have an impact on the performance of an organization, and how the efforts taken towards the improvement of MAPs have a direct positive impact on the overall performance of SMEs.
\end{abstract}

Keywords: Small and medium sized enterprises, MAPs, performance.

Cite this Article as: Mahdi Hasan Ahmed AlKhajeh and Azam Abdelhakeem Khalid (2018), " Management Accounting Practices (MAPs) Impact on Small and Medium Enterprise Business Performance within the Gauteng Province of South Africa ", Journal of Accounting and Auditing: Research \& Practice, Vol. 2018 (2018), Article ID 345766, DOI: 10.5171/2018. 345766 


\section{Introduction}

The article has focused majorly on the impact of MAPs over the small and medium sized enterprises (SMEs) of a South African province named Gauteng. SMEs are gaining a lot of weight these days in the field of management and with the researchers related to SMEs. SMEs are considered to play a vital role in the economic development of a country. SMEs are considered as one of the most important sources of employment generation in developing as well as developed countries. One of the most important advantages that these SMEs enjoy is that because of their small scale organization they are very flexible and hence are able to adopt any change quickly and efficiently. Because of this reason, SMEs are also considered as one of the fastest growing sectors in an economy (Love \& Roper, 2015). SME has a vast arena and a lot of research has been conducted over this topic in order to get a clear picture of its working, management, financial position, as well as productivity and performance and its impact on the economy as a whole. The authors of this article selected this topic as they felt that there is still a lack of knowledge when it comes to the impact of management accounting on the performance of SMEs in South Africa. Through this article the authors have attempted to provide an in-depth analysis of the impact of management accounting on the performance of SMEs.

\section{Research Objectives}

The main aim or objective of this research is to find out the impact of different MAPs like costing, budgeting, performance evaluation, information for decision making as well as strategic analysis on the performance of Small and Medium Enterprises.

\section{Research Question}

- What is the impact of MAPs on the business performance of SMEs?
- What is the impact of the costing system on the performance of SMEs?

- What is the impact of budgeting on the performance of SMEs?

- What is the impact of performance evaluation on the performance of SMEs?

- What is the impact of information for decision on the performance of SMEs?

- What is the impact of strategic analysis on the performance of SMEs?

\section{Literature Review}

The need for focusing on this topic came from the fact that the South African SMEs were failing because of lack of knowledge or because of ineffective use of the management practices. Ahmad (2012) has mentioned that one of the major reasons behind the failure of SMEs is the poor management practices adopted by the organizations. This article has included the work from several authors who have mentioned that management accounting is very important for the success of an organization and inefficient management accounting is a major cause of failure of many organizations (Ahmad, 2012). Because of this reason Maziriri and Mapuranga (2017) decided to research about this topic and come up with results and findings that can be of help to SMEs.

The definition of SMEs and management accounting is given by many different authors and entities. To mention a few definitions, according to Modimogale and Kroeze (2009), SMEs are those businesses that provide employment opportunities to less than 150 people and are not a part of any public limited company. SMEs definition in South Africa is that they are separate business entities which further include corporate enterprises as well as nongovernmental organizations which are run by a single person or more (Aminu \& Shariff, 2015). According to Talha, Raja, and Seetharaman (2010), management 
accounting provides financial as well as non financial information to the managers that help them in the decision- making process. So, from this it is clear that management accounting is used by the managers of a company to improve the performance of the organization by controlling its operations and activities.

The article has also mentioned the MAPs. MAPs according to Ndwiga (2010) aim to provide management solutions which can be used by the internal management of an organization. Information that can help in the decision- making process, performance evaluation, as well as budgeting forms a part of the MAPs (Gichaaga, 2014). The below article has also shown the relationship between MAPs and the performance of SMEs. The article states that MAPs have the ability to improve the efficiency of an organization's management, which leads to improved organizational performance (Maziriri \& Chinomona, 2016). With the help of MAPs organizations are able to survive in the highly competitive environment. Because of the ever- changing demands of the customers many changes are required to be adopted within the organization (Ahmad et al., 2013). MAPs help in such situations by providing the necessary information to the management which helps them remain flexible and easily adopt changes. It guides the actions of managers as well as motivates behaviors and also develops the culture of the organization to achieve the desired goals and objectives of the company (Mitchell \& Reid, 2000).

The organizations that adopt MAPs are able to avoid the chances of business failure in the future as MAPs provide the ability to the organization to compete in the market. According to a study conducted by Nuhu, Baird and Appuhami (2016), MAPs have a direct impact on the performance of the organization. The results of their study have shown that organizations that make use of contemporary MAPs are able to experience greater change within their organization and are able to perform strongly in the market.
So, from this it can be clearly said that with the help of MAPs organizations are able to adopt changes if and when necessary and are able to perform well in the market as well (Nuhu et al., 2016). So, it can be inferred that MAPs have a positive impact on the performance of SMEs and should be adopted by SMEs in order to improve their productivity and performance.

\section{Research Design and Methodology}

The Quantitative research method was used in this article in order to collect the results of the research. The main reason behind selecting the survey method was that it gave an opportunity to make use of questionnaires in order to collect data with an unbiased opinion and reflect what the respondents feel (Dhurup, 2014). The target population of this study was retail owners as well as the managing staff of the SMEs that were functioning in the South African province of Gauteng.

\section{Sampling Technique}

The sample frame for this article was SMEs that are functioning within the Vaal Triangle region where the survey was conducted in order to fulfill the objectives of the research. Sample frame can be understood as the actual study population. Probability sampling technique was used in this research as the sampling method. Simple random sampling technique was also used in this research in order to provide equal opportunity to the selected population to get selected as a part of the sample (Malhotra, 2010).

\section{Sample Size}

Historical sample size technique was used in order to select the sample size for conducting this research. The author used past studies in order to decide the sample size to be selected. The authors compared 5 past studies before deciding the sample size for the research. The main reason for studying past research for deciding the sample size was to get an idea as to what sample size is 
appropriate in order to conduct the survey on the selected topic and get the desired results. After analyzing the past studies the authors of this research selected a sample size of 345 and believed that this size will be sufficient to represent the SMEs. Four major factors were considered by the authors of the research before selecting the sample size, cost of the sampling, population variability, groups involved within the sample and the accuracy as well as information required for the results.

\section{Measures}

A well- structured self-administered questionnaire was prepared in order to conduct the survey. The questionnaire prepared was divided into seven different categories starting with the demographic questions in the first section and the rest of the sections included questions related to the independent variables of the research. Questions related to different independent variables were taken from different sources and the responses were represented by the use of the Likert scale where, 1 = strongly disagree and 5 =strongly agree. The questionnaire was distributed to different retail owners as well as SMEs of the South African province. Questions related to MAPs which include costing system, budgeting, performance evaluation, information as well as strategic analysis were taken from the works of Gichaaga, (2014 as well as from the study undertaken by Sunarni (2013). The questions related to the business performance of SMEs were taken from Maziriri and Chinomona (2016).

\section{Data Analysis and Results}

\section{Data Analysis}

The data collected by the survey analysis reflected the viewpoints of different retail owners as well as managers of SMEs in the Gauteng province of South Africa. 345 questionnaires were distributed and returned for survey analysis and out of these questionnaires only 280 questionnaires were in a condition to be used. Hence, a valid response of nearly 81 per cent of the respondents was collected. The descriptive analysis on the basis of the below table, reveals the gender and marital status of the respondents as well as the age of the retail owners and managers of the SMEs. On the basis of the analysis, it was found out that the ratio of female respondents was more as compared to male respondents. Females constituted $61 \%$ of the total population which is 170 , whereas males constituted $39 \%$ of the total population which is 110 . On the basis of the age group, it was found out that $64 \%$ of the respondents belonged to the $18-35$ years age group, $26 \%$ belonged to the $36-50$ years age group, whereas $10 \%$ of the respondents were above 51 years.

\section{Demographic Profile of the Respondents}

\begin{tabular}{|l|l|l|}
\hline Gender & Number & Percentage \\
\hline Male & 110 & 39 \\
\hline Female & 170 & 61 \\
\hline \hline Total & 280 & 100 \\
\hline \hline & & \\
\hline Age Group (In Years) & Number & Percentage \\
\hline $18-35$ & 180 & 64 \\
\hline $36-50$ & 73 & 26 \\
\hline Above 51 & 27 & 10 \\
\hline \hline Total & 280 & 100 \\
\hline \hline
\end{tabular}

Mahdi Hasan Ahmed AlKhajeh and Azam Abdelhakeem Khalid (2018), Journal of Accounting and Auditing: Research \& Practice, DOI: $10.5171 / 2018.345766$ 


\section{Results}

Out of the total questionnaires distributed, only 81 per cent of the questionnaires were in a position to be used. The demographic results of the research showed that 61 per cent of the respondents that participated in the research were females and a majority of the respondents fall in the age group of 18-35 years. Regression analysis was used in order to find out the impact of management accounting on the performance of the business (Mafini \& Meyer, 2016). Business performance is the dependent variable whereas the independent variables used in the regression analysis include budgeting, costing system, performance evaluation, information for decision making as well as strategic

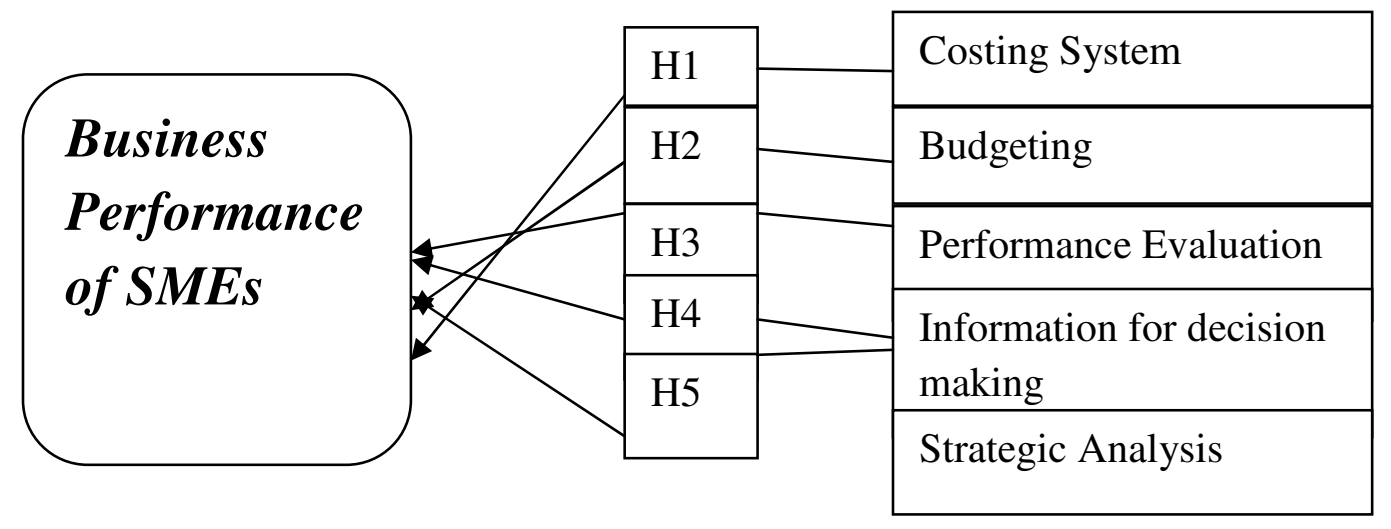

\section{Proposed Research Framework}

The model fit was measured with the help of coefficient of determination which is also known as R-square.

\section{Regression Analysis: MAPs and business performance}

\begin{tabular}{|lccc|}
\hline \multicolumn{4}{|c|}{ Dependent Variable: Business Performance } \\
Independent Variables: \\
Management account practices & & & \\
& Standardized Beta & $\mathrm{T}(\mathrm{t})$ & $\mathrm{Sig}(\mathrm{P})$ \\
\hline Costing System & 0.064 & 1.722 & 0.048 \\
Budgeting & 0.284 & 2.235 & 0.002 \\
Performance evaluation & 0.337 & 5.412 & 0.000 \\
Information for decision making & -0.163 & -1.139 & 0.001 \\
Strategic Analysis & 0.424 & 3.421 & 0.011 \\
\hline $\mathrm{R}=0.412$ Adjusted $\mathrm{R}^{2}=0.424$, & * Significant at the .05 level \\
\hline
\end{tabular}

According to the results of the regression analysis conducted in this research, it was found that the management practice that has been taken as the independent variable accounts for 42 per cent of the variance of business performance. But, from this it can be inferred that MAPs have an impact on the business performance of SMEs, and hence, it is very important that MAPs are implemented by SMEs for achieving success. Costing system has a positive impact on the performance of the organization, as well as it 
has been found that an increased involvement in the costing system has the ability to improve the performance of the organization. According to the regression analysis, it was found that budgeting improves the performance of SMEs. Hence, SMEs should focus on the budgeting process and consider these MAP very important. Performance evaluation has also positively affected the performance of the organization. The article has mentioned that, the more the owners of SMEs evaluate their performance the more are the chances that the organization can improve its performance. From the regression analysis it was found that information for decision making is not an important contributor of the performance of an organization. The result that has been found in this research related to the information for decision making is different from the results of other research studies conducted in the past. So, it can be inferred that the information for decision making may not be suitable for SMEs. With the help of the regression analysis it was found that strategic analysis is the strongest predictor of the organizations performance. Hence, it can be clearly stated that strategic analysis MAP has a very positive effect on the performance of the organization. Overall, by looking at the results it can be said that the MAPs have an influence on the performance of SMEs and efforts should be taken by the SMEs to adopt and implement MAPs in the organizations to improve the overall performance and compete in the economy.

\section{Research Limitation}

This study has been able to make significant contribution towards the concerned topic, but there are certain limitations related to this article. One such limitation is that this article is specific to the Gauteng province of South Africa and the data collected reflects geographical limitations, that is, the data may not be similar if the model is applied to another region or province.

\section{Discussion}

The following discussion aims to describe the results related to the regression analysis of the individual MAPs over the business performance of SMEs.

\section{Costing System}

On the basis of the above table related to the regression analysis, it can be said that there is positive effect of costing system on the performance of SMEs $(\beta=0.064 ; t=1.722 ; p$ $=0.048)$ and this result is in line with the research conducted by Elhamma and Zhang (2013), which says that the costing system has the ability to enhance the performance of SMEs.

\section{Budgeting}

Budgeting also has a significant impact on the performance of SMEs, $(\beta=0.184 ; t=2$.

$235 ; \mathrm{p}=0.002)$ and this has also been stated by the research work of Qi (2010) which revolved around the impact of budgeting MAP on SMEs in China.

\section{Performance Evaluation}

The regression analysis reveals that if the owners or the managers of SMEs take efforts to evaluate their performance it has a significant positive impact on the performance $\quad(\beta=0.337 ; t=5.412 ; p=0$. $000)$. This result was also obtained by Quresh and Hassan (2013).

\section{Information for Decision Making}

The regression analysis showed there is no significant impact of decision making on the performance of SMEs $(\beta=-0.163 ; t=-1.139$; $p=0.001)$. The results that were found through the regression analysis were contradicting with other researchers (Gilmore \& Carson, 2000). 


\section{Strategic Analysis}

A strong relationship was seen between the strategic analysis and the performance of SMEs, and on the basis of the regression analysis, it was found that this was the strongest predictor of the performance of the SMEs $(\beta=0.424 ; t=3.421 ; p=0.044)$. The results were also supported by the results of the study conducted by Parnell (2013), which reveal the strong relationship being shared by strategic analysis MAP and business performance (Parnell, 2013).

\section{Conclusion}

In the end, it can be concluded that the authors of this article have used both the primary as well as secondary sources in order to fulfill the objectives of the research. With the help of the previous literatures, the authors were able to find out the relation between the MAPs and their impact on the performance of SMEs. The authors used different MAPs like costing, budgeting, information for decision making, performance evaluation as well as strategic analysis in order to find out the impact of these practices on the performance of the company. With the help of regression analysis, the authors were able to showcase the individual impacts of these MAPs on the performance of the company. This research has validated that the MAPs have an impact on the performance of an organization. It has also mentioned that an increase in the usage of these MAPs has the ability to increase the performance and productivity of the organizations. This research is successful in showcasing both the theoretical as well as managerial implications. Through this study, it can be said that a remarkable progression has been made in the management accounting concepts, and with the help of different methods the relationship between the MAPs and the business performance has been showcased. This article can be used by future researchers, as it has highlighted different aspects of the MAPs with reference to their importance and effect on the performance of SMEs. This research can be used as a reference to other experts who want to undertake research on the topic: The impact of MAPs on the performance of SMEs. This is so because the authors of this research have supported their statement with valid evidence using different methods as well as the survey analysis done by the authors. This research will also add in the development of SMEs, as it has clearly showcased the impact of different MAPs on the performance of SMEs that have been surveyed in the region of South Africa (Maziriri \& Mapuranga, 2017).

\section{References}

1. Ahmad, K. (2012) The use of MAPs in Malaysian SMEs. South West England, United Kingdom: Doctor of Philosophy in Accountancy, University of Exeter.

2. Ahmad, Kamilah \& Zabri, M. (2013), 'The relationship between the use of MAPs and the performance of Malaysian medium-sized enterprises,' 2nd International Conference on Global Optimization and Its Applications 2013 (ICoGOIA 2013), , 2013, Melaka, Malaysia. UTHM Institutaional Repository.

3. Aminu, I.M. \& Shariff, M.N.M. (2015), 'Determinants of SMEs performance in Nigeria: A pilot study,' Mediterranean Journal of Social Sciences, 6 (1), 156-64.

4. Dhurup, M. (2014), 'Impulsive fashion apparel consumption: the role of hedonism, fashion involvement and emotional,' Mediterranean Journal of Social Sciences, 5(8), 168-77.

5. Elhamma, A. \& Zhang, Y.I. (2013) 'The relationship between activity based costing, business strategy and performance in Moroccan enterprises,' Accounting and Management Information Systems, 12 (1), 2238.

6. Gichaaga, P.M. (2014) Effects of MAPs on financial performance of manufacturing companies in Kenya. Nairobi: Master of Science in Finance Dissertation, School of Business, University of Nairobi. 
7. Gilmore, A. \& Carson, D. (2000), 'The Demonstration of a Methodology for Assessing SME Decision Making,' Journal of Research in Marketing and Entrepreneurship, 2(2), 108-24.

8. Love, J.H. \& Roper, S. (2015), 'SME innovation, exporting and growth: A review of existing evidence. International Small Business Journal: Resaerching Entrepreneurship, 33 (1), 28-48.

9. Mafini, C. \& Meyer, D. (2016), 'Societal Factors and Life Satisfaction: Evidence from Low Income Urban Societies in a Developing Country,' Journal of Economics and Behavioral Studies, 8 (3), 87-110.

10.Malhotra, N.K. (2010) Marketing Research: An Applied Orientation. New Jersey: Prentice Hall.

11.Maziriri, E.T. \& Chinomona, E. (2016), 'Modeling the Influence of Relationship Marketing, Green Marketing and Innovative Marketing on the Business Performance of Small, Medium and Micro Enterprises (SMMES),' Journal of Economics and Behavioral Studies, 8 (3), 127-39.

12.Maziriri, E.T. \& Mapuranga, M. (2017), 'The Impact of MAPs (MAPs) on the Business Performance of Small and Medium Enterprises within the Gauteng Province of South Africa,' The Journal of Accounting and Management, 7 (2), 12-25.

13.Mitchell, F. \& Reid, G.C. (2000), 'Problems, challenges and opportunities: the small business as a setting for management accounting research. Management Accounting Research, 11 (4), 385-90.

14.Modimogale, L. \& Kroeze, J.H. (2009), 'Using ICTs to become a competitive SME in South Africa' Proceedings of the 13th International business information management association conference on Knowledge Management and Innovation in Advancing Economies: Analyses \& Solutions 2009, IBIMA.
15.Ndwiga, N.M. (2011) The role management accounting in creating and sustaining competitive advantage : a case study of Equity Bank, Kenya. Pretoria: Master of Commerce in accounting dissertation, University of South Africa.

16.Nuhu, N.A., Baird, K. \& Appuhami, R. (2016), 'The Association between the Use of MAPs with Organizational Change and Organizational Performance,' In M.J. Epstein \& M.A. Malina, eds. Advances in Management Accounting. Emerald Group Publishing Limited. pp.67-98.

17.Parnell, J.A. (2013), 'Uncertainty, Generic Strategy, Strategic Clarity, and Performance of Retail SMEs in Peru, Argentina, and the United States,' Journal of Small Business Management, 51 (2), 215-34.

18.Qi, Y. (2010), 'The Impact of the Budgeting Process on Performance in Small and MediumSized firms in China,' [Online], [Retrieved May 28, 2018], https://ris.utwente.nl/ws/portalfiles/portal /6082450

19.Qureshi, A. \& Hassan, M. (2013), 'Impact of performance management on the organisational performance: An analytical investigation of the business model of McDonalds,' International Journal of Academic Research in Economics and Management Sciences, 2 (5), 54-75.

20.Sunarni, C.W. (2013), 'MAPs and the Role of Management Accountant: Evidence from Manufacturing Companies throughout Yogyakarta, Indonesia,' Review of Integrative Business and Economics Research, 2 (2), 616626.

21.Talha, M., Raja, J.B. \& Seetharaman, A. (2010), 'A New Look At Management Accounting,' Journal of Applied Business Research, 26 (4), 83-96. 